\title{
Febrile encephalopathy
}

\author{
Pratibha Singhi ${ }^{1}$, Naveen Sankhyan ${ }^{1}$ \\ ${ }^{1}$ Advanced Pediatrics Centre, Department of Pediatrics, Post Graduate Institute of Medical Education and Research \\ Corresponding author: Pratibha Singhi; E-mail: doctorpratibhasinghi@gmail.com
}

\begin{abstract}
Febrile encephalopathy can be due to various causes that vary according to the local epidemiology and season. The critical window for diagnosis and effective intervention is often short. The basic principles of management include; the initial assessment and stabilization, focussed clinical evaluation and neurological assessment. Raised intracranial pressure, seizures and hemodynamic instability if present must be managed immediately and appropriately. Often the diagnosis or specific etiology is not immediately apparent, and empiric therapy based on local disease prevalence is initiated in the emergency room. Clinical evaluation and investigations then aid in the diagnosis and more specific management. Keywords: altered sensorium, altered consciousness, neuroinfections, impaired consciousness, encephalitis, meningoencephalitis, meningitis
\end{abstract}

(C) 2018 Singhi \& Sankhyan; licensee JICNA

\section{INTRODUCTION}

Febrile encephalopathy is a syndromic diagnosis that includes all patients with fever and altered consciousness. This review focuses on providing a overview of febrile encephalopathy in children and is targeted at physicians and trainees working in tropics. This article is a pragmatic approach to the subject and though the relevant evidence based guidelines have been reviewed, a detailed evidence based review on the subject is beyond the scope of this article. For a more detailed review on individual entities the reader is referred to some recent reviews.[1-4]

\section{ETIOLOGY (TABLE 1)}

The potential causes for a child with fever and encephalopathy are numerous. However, central nervous system (CNS) infections are the most common cause of fever associated encephalopathy in children in the tropics.[5-8] The infectious causes of acute febrile encephalopathy vary widely in different regions of the world and this can have a bearing on the empirical therapy as well. (Table 1) From a clinical perspectiveit is useful to combine and categorize the causes of febrile encephalopathy into: (Table 2)

1. Febrile encephalopathy with meningeal signs

2. Febrile encephalopathy without meningeal signs While the above is suggested, children especially infants and those severely ill may not have meningeal signs despite a meningeal infection or inflammation. $[9,10]$ Children with meningeal signs usually have an infectious cause for encephalopathy, although occasionally meningeal signs may result from parainfectious inflammation too.[11] Children who have altered consciousness but no meningeal signs can have diverse causes for encephalopathy. (Table 2) Some of these causes can co-exist in an individual child

If the child has a congenital or acquired immunodeficiency the etiological organisms causing neuro-infections vary considerably.[12] Patients with defects in cell-mediated immunity are most susceptible to CNS infections by micro- organisms that are intracellular parasites, the eradication of which depends on an intact T-lymphocyte-macrophage system. L. monocytogenes is the most common cause of bacterial meningitis in patients with defective cell-mediated immunity. This includes children with hematological malignancies, organ transplantation, cancer and cancer chemotherapy, human immunodeficiency virus (HIV) infection, and chronic corticosteroid therapy.[12] Patients with defective humoral immunity are unable to mount an antibody response to a bacterial infection and are therefore unable to control infection caused by polysaccharide-encapsulated bacteria such as Strep pneumoniae.[13] Apart from bacterial agents several viruses can get reactivated in immuno-compromized hosts these include; HSV, varicella, HHV-6, CMV, JC virus etc. Apart from these immuno-compromized are also predisposed to various other infections which do not generally occur in immuno-competent host e.g. fungal infections (e.g.Cryptococcus)[14] or protozoan infections (e.g. toxoplasmosis) etc.

\section{CLINICAL EVALUATION}

Febrile encephalopathy is a medical and neurological emergency. The management of an encephalopathic child requires immediate life support (refer to PALS guidelines)[15], efforts to identify cause, and institution of specific therapy. In clinical situations, the evaluation (clinical as well as investigations) and treatment have to proceed simultaneously (Figure 1, Table 3).

\section{History}

A careful history should be taken with special emphasis on the events prior to the onset of encephalopathy. Presence of headache, vomiting, irritability, seizures, rash and the duration of symptoms must be enquired. The history of fever or recent illness suggests an acute infectious etiology (sepsis, meningitis, encephalitis), but other disorders that occur 
during or after an infectious illness should also be considered. These include post infectious demyelinating encephalomyelitis, Reye's syndrome, inborn errors of metabolism worsened or precipitated by an intercurrent infection. History of past medical illnesses and family history must also be elicited. Children with inborn errors of metabolism, pre-existing chronic organ failures such as chronic kidney disease or hepatic failure can worsen during inter-current infections and present as febrile encephalopathy.

History should also include points that may provide clues to specific conditions, such as history of dog bite (rabies), oral ulcers (enteroviral), diarrheal illness(enteroviral), endemicity (dengue, Japanese encephalitis), recent travel, rash, focal signs, aphasia, or prominent behavioural changes(herpes encephalitis).

All febrile illnesses are not due to infections. Infection triggered inflammatory encephalomyelitis can occur after seemingly minor childhood infections and so a history of recent infections or immunizations should be carefully sought. [16] A history of environmental exposure to high temperatures should be sought to exclude heat stroke. A history of drug and toxin exposure can help diagnose unsuspected toxic causes of febrile encephalopathy. The toxins/drugs generally impair sweating and predispose to fever and encephalopathy. The child may be exposed to drugs available at home and used by adults. Hence, a detailed enquiry into the various drugs that are available at home should be made. The common agents that result in fever are anticholinergics, antihistaminics, antipsychotics, salicylates, diuretics, antiparkinsonian drugs, and antidepressants. [17]

\section{Examination}

The examination of vital signs and general physical examination may provide important clues to the status and the possible etiology of febrile encephalopathy (Table 4). Systemic examination may further clarify on the possible etiology of the encephalopathy. Chest examination is helpful to detect underlying pneumonia or empyema. Cardiovascular examination may suggest congenital or rheumatic heart disease, both of which predispose the patient to endocarditis and subsequent intracranial abscess. Abdominal examination is important to detect hepatosplenomegaly which may be present in many infective conditions and liver disease.

\section{Neurological examination}

The neurological examination gives important information about the potential causes and localization of brain dysfunction. The immediate focus of examination is to identify signs of potentially life threatening raised ICP and brain herniation syndromes.[18] Identification of a herniation syndrome indicates an immediate need for intervention and deferring further evaluation till child is stabilized. The Glasgow coma scale is the most popular coma scale and helps quantify and communicate the changes in depth of coma.[19] Neck rigidity in the setting of febrile encephalopathy indicates meningitis, meningo-encephalitis or tonsillar herniation. The Kernig's and Brudzinski's signs are more reliable signs of meningeal irritation than neck stiffness, which may also result from local pathologies.[20]

The other priority is to identify possible clues to the etiology, for example presence of extrapyramidal signs in a relevant epidemiological setting could suggest Japanese encephalitis. Involvement of the spine cord may indicate a demyelinating disorder or an infection with predilection for cord (anterior horn cells in Rabies, Japanese encephalitis, enteroviral infection).[21] The setting and local epidemiology is important to interpret examination findings, e.g. presence of meningeal signs, focal signs with or without extrapyramidal signs in a child with prolonged fever may also suggest a tubercular meningitis.

\section{INVESTIGATIONS}

\section{First line investigations}

Blood glucose estimation during the process of obtaining the first intravenous access and other investigations are done on first contact in the emergency room (Figure 1). The initial testing including peripheral smear and rapid diagnostic test for malarial parasite or dengue or both, and subsequent work up for infections should be based on local epidemiology. (Table-5). Acute phase blood and serum sample should be stored for further investigation as deemed necessary based on the clues obtained from clinical evaluation and the initial investigations. $=$

A lumbar puncture and cerebrospinal fluid (CSF) examination is the most important investigation and should be done as soon as possible, once the child is stabilized.CSF should be tested for cell count, glucose, protein, Gram stain, Ziehl-Neelson stain, bacterial culture, viral polymerase chain reaction for Herpes Simplex virus, Latex agglutination test, and additional cultures guided by clinical suspicion (fungal or tubercular). A broad-range PCR can detect small numbers of viable and nonviable organisms in CSF. When the broad-range PCR is positive, a PCR that uses specific bacterial primers to detect the nucleic acid of $\mathrm{S}$. pneumoniae, $\mathrm{N}$. meningitidis, E. coli, L. monocytogenes, H. influenzae, and Streptococcus agalactiae should be done (Table-6). Lumbar puncture should be deferred, if clinical or radiologic evidence is present for intracranial hypertension, is otherwise contra-indicated (thrombocytopenia, shock, local infection). In all such children empirical therapy based on local disease epidemiology and seasonal trends should be instituted without delay. (Figure 1, Table 3)

CT head has the risk of radiation exposure but the short imaging time is its advantage. MRI, though better, is not universally available and the long acquisition time entails the risk of sedation and destabilization of a comatose child. Hence CT is often the first neuroimaging in children presenting to the emergency room. A normal CT does not exclude raised intracranial pressure and can miss findings of viral encephalitis.[22,23] In non emergent situations a MRI is preferred and would be better at defining the extent and severity of involvement in neuroinfections and other non-infectious conditions of the brain.(Kirkham DMCN) In more emergent situations a CT scan should be obtained prior to lumbar puncture in the following situations: 1) focal neurological deficit; 2) new onset seizure; papilledema; 4) abnormal level of consciousness; and 5) immuno-compromised state .[24] CT is helpful in looking for features of intracranial infections like encephalitis, subdural empyema, complications of intracranial infections such as stroke, brain herniation and cerebral edema. A contrast study may reveal features of infection such as meningeal enhancement, brain abscess or tuberculoma. In cases of uncomplicated meningitis, cranial computed tomography is sufficient to exclude brain edema, hydrocephalus, and skull base pathology.[25] 


\section{Second-line Investigations}

These investigations are done after initial stabilization and after the first line investigations.

MRI Brain: MRI is better at defining the extent and severity of involvement in neuroinfections and other non-infectious conditions of the brain. Diffusion-weighted imaging (DWI) detects lesions early in patients with viral encephalitis, and in cases with parenchymal complications of meningitis. It is of help in differentiation of pyogenic abscess from other ring-enhancing lesions. It provides evidence of fronto-temporal pathology in herpes simplex encephalitis, thalamic involvement in Japanese-B encephalitis, demyelination in ADEM, or necrotizing lesions in acute necrotizing encephalopathy.[26] MRI is superior to CT in early detection of signs of Herpes encephalitis, which can be demonstrated within the first 48 hours on T2WI or FLAIR images.[27] Magnetic resonance imaging of EV71 encephalitis typically shows hyperintense lesions on T2WI located within the brainstem and dentate nuclei of the cerebellum.[28] It may also provide clue to the diagnosis of rarer infections like cryptococcal, fungal or amoebic affection of the brain. The severity of involvement detected on an MRI may also aid in prognostication.[25]Proton magnetic resonance spectroscopy can produce specific peak-patterns in cases of abscess, such as the presence of lactate and cytosolic amino acids.[25]

Electroencephalogram (EEG): Specific abnormalities on EEG may include epileptiform activity consistent with complex partial status; triphasic waves indicating hepatic or uremic encephalopathy; and periodic lateralizing epileptiform discharges, suggesting herpes encephalitis or other focal encephalitides.[29] More commonly non specific abnormalities like diffuse theta and delta activity, absence of faster frequencies, and intermittent rhythmic delta activity are seen. There is growing evidence that electrographic seizures may contribute to brain injury and worsen outcome. Most electrographic seizures would go unnoticed even with careful clinical observation, and therefore require CEEG monitoring for their detection. Hence, when resources permit, continuous EEG must be done for all children with acute encephalopathy.[30]

Metabolic testing: In cases of unexplained or recurrent encephalopathy, blood ammonia, urine and blood samples for amino and organic acid disorders, free fatty acid and carnitine levels should be obtained. The sampling of the child in acute phase, before starting treatment and stopping feeds has more yield.[31] However, treatment should not delayed in a sick child with suspicion of inborn error of metabolism solely for the purpose of sampling. In resource limited settings empirical treatment with vitamins and co-factors can be started pending investigations and referral to a more equipped centre.

\section{TREATMENT}

Children with febrile encephalopathy are best cared for in the pediatric ICU settings, however this facility is often unavailable to many children managed in the developing countries. Though, principals of management remain the same, interventions like continuous $\mathrm{BP}$, continuous EEG or invasive ICP monitoring and MRI may not be available to guide treatment. Despite this fact many interventions that are not resource intensive can be easily applied in resource limited settings. (Table 7) In situations where these basic interventions cannot be done, therapy should be initiated and preparation for shifting the child to a more equipped facility undertaken.
Management of a child with febrile encephalopathy usually proceeds simultaneously with the clinical evaluation and the investigative workup (Figure 1). As for all sick children coming to the emergency room, the Pediatric advanced life support (PALS) guidelines should be followed.[15] The goals of treatment are:

- Stabilization of vitals: airway, breathing and circulation

- Identify and treat hypoglycemia with intravenous dextrose

- Identification and treatment of brain herniation and raised intracranial pressure: [The complete management guidelines for the management of raised ICP are beyond the scope of this review and the reader is referred to recent publications on this topic.[32,33]

- Identification and treatment of seizures. Non convulsive status epilepticus (NCSE) may be seen in comatose children, and should be looked for in all children with unexplained persistent encephalopathy.

- Maintenance of normothermia.

- Correction of acid base and electrolyte abnormalities In case of suspected sepsis/ meningitis, broad spectrum antibiotics (ceftriaxone, vancomycin) should be instituted immediately. If viral encephalitis is likely, then samples for PCR for herpes simplex virus should be sent and acyclovir [32] should be started. Antimalarials (quinine/ artesunate) should be started if there is a clinical suspicion of cerebral malaria.

Steroids are of benefit in acute disseminated encephalomyelitis, meningococcemia with shock, enteric encephalopathy, tubercular meningitis, and pyogenic meningitis.

If metabolic causes have been identified, e.g. diabetic ketoacidosis, hepatic encephalopathy, uremia or hyperammonemia, these should be treated appropriately.

In sick children with acute febrile encephalopathy, empirical therapy with antibiotics, acyclovir and antimalarial agents should be considered while the results of investigations are awaited (See Figure 1). The clinical course of the child should be monitored closely and documented. Particular attention should be paid to changing level of consciousness, fever, seizures, autonomic nervous system dysfunction, and increased intracranial pressure. Health care associated infections are important complications during hospitalization, and must be prevented and treated promptly.

\section{CONCLUSIONS}

The causes of febrile encephalopathy in children are numerous and have a geographic and seasonal variation. A child with febrile encephalopathy should be quickly assessed for life threatening signs. Further evaluation should wait until immediate life threatening conditions are managed. The initial assessment and stabilization should be followed by focussed clinical evaluation and neurological assessment. Empiric therapy is based on local disease prevalence. A more specific management can be followed after a diagnosis is established or is reasonably certain. Most children with febrile encephalopathy are best managed in an ICU, however basic management can be undertaken in resource limited settings as well. 


\section{Acknowledgments}

None.

\section{Competing interests}

The authors declare that they have no competing interests.

\section{Author contributions}

PS and NS reviewed the literature. NS drafted the initial manuscript which was revised and finally approved by PS
This is an Open Access article distributed under the terms of the Creative Commons Attribution License (http://creativecommons.org/ licenses/by/4.0), which permits unrestricted use, distribution, and reproduction in any medium, provided the original work is properly credited. The Creative Commons Public Domain Dedication waiver (http://creativecommons.org/publicdomain/zero/1.0/) applies to the data made available in this article, unless otherwise stated.

\section{Cite this article as:}

Singhi \& Sankhyan: Febrile encephalopath. JICNA 2018 18:11

Table 1: Variation in etiological agents/diseases causing acute febrile encephalopathy based on geographical exposure [1, 5-8, 35-39]

\begin{tabular}{ll} 
Africa & $\begin{array}{l}\text { Malaria, pyogenic meningitis (pneumococcal, H influenza B due to poor vaccine coverage), HIV } \\
\text { related CNS infections, Enteric fever, Dengue, Tuberculous meningitis, Trypanosomiasias }\end{array}$ \\
\hline Asia & $\begin{array}{l}\text { Japanese Encephalitis Virus, pyogenic meningitis (pneumococcal, H influenza B in areas with poor } \\
\text { vaccine coverage), Malaria, Dengue, Tuberculous meningitis, Scrub typhus, Enteric fever, Nipah } \\
\text { virus }\end{array}$ \\
\hline $\begin{array}{l}\text { Australia } \\
\text { Europe }\end{array}$ & $\begin{array}{l}\text { Murray Valley encephalitis virus, Kunjin virus, Australian Bat Lyssavirus } \\
\text { Central and South } \\
\text { America }\end{array}$ \\
\hline
\end{tabular}

North America $\quad$ Arboviruses (eg, WNV, Powassan, LaCrosse, Eastern Equine Encephalitis viruses), Lyme disease

Table 2: Selected causes of febrile encephalopathy in children Febrile encephalopathy with meningeal irritation

- Meningitis

- Meningo -Encephalitis

- Acute disseminated encephalomyelitis

Febrile encephalopathy without meningeal irritation*

- Infectious encephalopathies: Shigella encephalopathy, Enteric encephalopathy, Cerebral malaria, dengue, Rickettsial: Lyme disease, Rocky mountain spotted fever

- $\quad$ Systemic Infections: severe gram-negative sepsis, toxic shock syndrome

- Infections with complications such as Stroke, Venous thrombosis, metabolic derangements (fluid \&electrolyte disturbances (dehydration, hyponatremia, hypernatremia, hypoglycaemia)

- Metabolic disorders: (decompensated or precipitated by the intercurrent infection):, Diabetic keto-acidosis, Reye syndrome, inborn errors of metabolism
- Organ failures with intercurrent infections: Uremia, Hepatic failure

- Post infectious disorders: Acute disseminated encephalomyelitis, Hemorrhagic shock and encephalopathy syndrome

- Post immunization encephalopathy: Whole cell pertussis vaccine, Semple Rabies vaccine

- Drugs and toxins- Anticholinergics

- Post prolonged convulsive status epilepticus

- Heat stroke

${ }^{*}$ Remember that infants and severely ill children may not have meningeal signs despite a meningeal infection or inflammation 
Table 3: Selected conditions that present with febrile encephalopathy in tropics [23]

CONDITION

Pyomeningitis

Viral meningoencephalitis encephalomyelitis

Scrub typhus

2-3rd week of typhoid fever

Tuberculous meningitis diagnosis frequently accompany$$
\text { -3rd week of typhoid fever }
$$

KEY FEATURES

Acute presentation with fever and meningeal signs, CSF shows high opening pressure, often cloudy, cells 100-5000 or more, polymorphs predominate, CSF sugar $<50 \%$ of blood sugar, Protein elevated, CSF and blood culture important for bacterial isolation

Epidemiological factors important for etiology, CSF: Clear, cells 5-1000, lymphocytes predominate, CSF sugar normal, Protein normal or mildly elevated. MRI may show diagnostic findings[23]

Epidemiological factors important, no meningeal signs, Retinopathy [42] , RDT have high sensitivity for

Presence of preceding viral illness optic neuritis or myelitis, are clinical clues, MRI is diagnostic

In Asia pacific region, Febrile multiorgan symptomatology, rash, eschar(diagnostic), transaminitis, thrombocytopenia and/or hyponatremia

Prolonged fever, meningeal signs, focal deficits and frequently a contact with adult tuberculosis patient, CSF shows high opening pressure, cells 100-500 Lymphocytes predominate, CSF sugar $<50 \%$ of blood sugar, Protein elevated (1-5g), Neuroimagingoften diagnostic shows basal exudates, hydrocephalous and infarcts, search for extraneural tuberculosis

\section{KEY INTERVENTIONS}

Early and high dose antibiotics [24]

Emperic treatment for HSV, until excluded by CSF DNA PCR. [40]

Early use of intravenous antimalarials

High dose pulse steroids

Rapid often dramatic response to Doxycycline [42]

intravenous antibiotics and intravenous Dexamethasone [43]

Antitubercular treatment, steroids and management of hydrocephalous [44]

Table 4: Clues to etiology of febrile encephalopathy on examination of vitals and general physical examination

\begin{tabular}{|c|c|}
\hline LOOK FOR & IF PRESENT, THINK OF \\
\hline Tachycardia & Fever, hypovolemic or septic shock, heart failure or arrhythmias \\
\hline Bradycardia & $\begin{array}{l}\text { Raised intracranial pressure or a result of myocardial injury (due to myocarditis, hypoxia, } \\
\text { sepsis, or toxins) }\end{array}$ \\
\hline Tachypnea & $\begin{array}{l}\text { With respiratory distress: Lung pathology e.g. pneumonia, pneumothorax, or empyema } \\
\text { Quiet tachypnea: acidosis which may be present in diabetic ketoacidosis, uremia, or some } \\
\text { poisonings (e.g. salicylate) }\end{array}$ \\
\hline Hypertension & Increased intracranial pressure, primary or secondary hypertension \\
\hline Hypotension & Sepsis, cardiac dysfunction, toxic ingestion, or adrenal insufficiency (meningococcemia) \\
\hline Pallor, spelenomegaly & Cerebral malaria \\
\hline Icterus & Hepatic encephalopathy, leptospirosis, complicated malaria, Rickettsial diseases \\
\hline Rashes & Meningococcemia, Dengue, Measles, Rickettsial diseases, Arboviral diseases \\
\hline Petechiae & Dengue, Meningococcemia, Viral Hemorrhagic fevers \\
\hline $\begin{array}{l}\text { Abnormal Odour of } \\
\text { exhaled breath }\end{array}$ & Diabetic ketoacidosis, hepatic coma \\
\hline
\end{tabular}


Table 5: Serological tests for an infectious etiology of altered consciousness [13] (with permission)

IgM and IgG antibodies for

- St Louis encephalitis virus

- West Nile encephalitis virus*

- Eastern equine encephalitis virus

- Western equine encephalitis virus

- Japanese encephalitis virus

- Dengue virus

- Epstein-Barr virus

- Human herpesvirus type 6

- Cytomegalovirus

- Rabies virus

- Human immunodeficiency virus

- Tick-borne bacterial infection**

- $\quad \lg \mathrm{G}$ and IgM by indirect immunofluorescence for Rocky Mountain spotted fever

- Lyme enzyme-linked immunosorbent assay (ELISA) - positive ELISA results should be confirmed by Western blot

- Ehrlichial antibodies by indirect fluorescent antibody test (IFA)

*West Nile virus IgM and IgG antibody titers that are positive by ELISA should be confirmed by the more specific plaque-reduction neutralization assay and cell culture.

${ }^{\star *}$ In addition to IFA for rickettsial and ehrlichial infections there are increasing numbers of ELISAs and flow immunoassays available, as well as polymerase chain reaction.

Table 6: Cerebrospinal fluid diagnostic studies for an infectious etiology of altered consciousness[13] (with permission) Basic tests

- $\quad$ Cell count with differential

- Glucose and protein concentration

- Stain and culture

- Gram's stain and bacterial culture

More specific tests

- India ink and fungal culture

- Viral culture

- Acid fast smear and M. tuberculosis culture

- Antigens: Cryptococcal polysaccharide antigen, Histoplasma polysaccharide antigen

Polymerase chain reaction (PCR)

- Broad-range bacterial PCR

Specific meningeal pathogen PCR

- $\quad$ PCR for Mycobacterium tuberculosis

- Reverse-transcriptase PCR (RT-PCR) for enteroviruses

- $\quad$ PCR for herpes simplex virus type 1 and 2

- $\quad$ PCR for West Nile virus

- $\quad$ PCR for Epstein-Barr virus

- PCR for varicella zoster virus

- $\quad$ PCR for cytomegalovirus DNA

- $\quad$ PCR for human immunodeficiency virus RNA

- RT-PCR for rabies virus

Antibodies

- Herpes simplex virus (serum:cerebrospinal fluid antibody ratio <20:1)

- Arthropod-borne viruses

- Borrelia burgdorferi

- Coccidioides immitis complement fixation antibody

- Rabies virus 
Table 7: Minimum essential work up and management of a child with acute febrile encephalopathy in resource constraint settings

\begin{tabular}{|c|c|}
\hline $\begin{array}{l}\text { Clinical } \\
\text { evaluation }\end{array}$ & Thorough history and examination \\
\hline Investigations & $\begin{array}{l}\text { Blood sugar, CBC with platelets, MP slide/RDT, LFT, KFT, dengue card test, blood culture, urine sugar } \\
\text { and ketones, Electrolytes, CT head, CSF: cytology, biochemistry, culture }\end{array}$ \\
\hline $\begin{array}{l}\text { Supportive } \\
\text { care }\end{array}$ & $\begin{array}{l}\text { Establish and maintain airway } \\
\text { - } \quad \text { Support ventilation and oxygenate as indicated } \\
\text { - } \quad \text { Circulation: Establish IV access, take samples } \\
\text { - } \quad \text { Fluid bolus if in circulatory failure, inotropes if required, treat electrolyte abnormalities if identified } \\
\text { - } \quad \text { Identify signs of cerebral herniation or raised ICP and manage accordingly* } \\
\text { - } \quad \text { Treat Seizures and fever or hypothermia }\end{array}$ \\
\hline $\begin{array}{l}\text { Specific } \\
\text { treatment }\end{array}$ & $\begin{array}{l}\text { Empirical treatment: (based on epidemiology, season ) } \\
\text { - Ceftriaxone } \pm \text { Vancomycin (other antibiotics may be indicated like doxycycline for Rickettsial } \\
\text { disease) } \\
\text { - Antimalarials(Quinine/ Artesunate)- Smear positive, RDT positive cases, Empiric treatment if } \\
\text { resident ofP.falciparum endemic area\#, short history ( }<48 \mathrm{hrs} \text { ), absent meningeal signs, anemia, } \\
\text { hypoglycemia, retinal hemorrhages } \\
\text { - Acyclovir-In sporadic Meningo-encephalitis with or without: focal neurological findings, behavior } \\
\text { changes, aphasia, suggestive CT (fronto-temporal changes), hemorrhagic CSF } \\
\text { - Steroids-: meningococcemia with shock, enteric encephalopathy, ADEM }\end{array}$ \\
\hline
\end{tabular}

IV- intravenous, CBC- Complete blood count, MP- malarial parasite, RDT- Rapid Diagnostic test for malaria, LFT- liver function test, KFT- Kidney function test, ICP- Intracranial pressure, CSF- cerebro spinal fluid, ADEM- Acute disseminated encephalomyelitis

*-measures such as nursing with head end elevated, avoiding sharp angulations of neck, sedation, controlling fever, maintaining normal BP, blood sugar, and oxygenation, avoiding painful procedures Cautious use of Glycerol (bacterial meningitis), mannitol and hypertonic saline.[33] 
Figure 1: A Step Wise Approach to a Child with Febrile Encephlalopathy

\section{STEP 1}

Follow PALS guidelines[15] for initial management

- Establish and maintain airway

- Ventilate and oxygenate as indicated

- $\quad$ Circulation: Establish IV access, take samples (blood sugar, CBC with platelets, MP slide/RDT, LFT, KFT, dengue card test, Blood culture, serum sample for pertinent serological tests, urine sugar and ketones, Electrolytes, Arterial Blood gas)

- Fluid bolus if in circulatory failure, inotropes if required, treat elctrolyte abnormalities if identified

- Identify signs of cerebral herniation or raised ICP; If any of following present, follow guidelines for management of raised ICP)[32]

- Treat Seizures and fever or hypothermia

\section{STEP 2}

Clinical evaluation: Thorough history and focused examination

\section{STEP 3}

Empirical treatment: (This would vary according to the local disease epidemiology and the season of occurrence)

- Ceftriaxone \pm Vancomycin (other antibiotics may be indicated like doxycycline for Rickettsial disease)

- Acyclovir-In sporadic Meningo-encephalitis with or without: focal neurological findings, behavior changes, aphasia, suggestive CT (fronto-temporal changes), hemorrhagic CSF

- $\quad$ Steroids-: meningococcemia with shock, enteric encephalopathy, ADEM

- Antimalarials(Quinine/ Artesunate)- Smear positive, RDT positive cases, empiric treatment if resident of P.falciparum endemic area\#, short history ( $<48 \mathrm{hrs}$ ), absent meningeal signs, anemia, hypoglycemia, retinal hemorrhages

\section{STEP 4}

Investigations

- $\quad$ CT: in patients with: f/o raised ICP, focal neurological deficits, features of herniation, may be diagnostic e.g. TBM, Brain abscess

- Lumbar puncture(LP): (if LP is delayed/contraindicated, start empirical treatment as indicated), Cytology, biochemistry, culture, Latex Agglutination, Duration of illness > 1 week: AFB stain, PCR for TB, Viral PCR, Jap B IgM

- Other specific tests (based on local epidemiology): Dengue serology, Widal, Serology for other pathogens; Leptospira, Mycoplasma, Rickettsia

- MRI for suspected encephalitis, demyelination

- $\quad$ EEG

- Metabolic testing: blood ammonia, acylcarnitine profile (TMS), urine organic acids

Monitoring for systemic and neurological function (tailored to the patients disease and severity of illness)

- Cardiovascular monitoring

- Monitoring for metabolic derangements

- $\quad$ Cerebral function monitoring; ICP monitoring, CEEG, cerebral blood flow monitoring

\section{REFERENCES}

1. Venkatesan A, Tunkel AR, Bloch KC, et al; International Encephalitis Consortium. Case definitions, diagnostic algorithms, and priorities in encephalitis: consensus statement of the international encephalitis consortium. Clin Infect Dis. 2013 ;57:1114-28.

2. van Toorn R, Solomons $R$. Update on the diagnosis and management of tuberculousmeningitis in children. Semin Pediatr Neurol. 2014;21:12-8.

3. Brouwer MC, Tunkel AR, van de Beek D. Epidemiology, diagnosis, and antimicrobial treatment of acute bacterial meningitis. Clin Microbiol Rev. 2010;23:467-492.

4. Guidelines for the Treatment of Malaria. 3rd edition. Geneva: World Health Organization; 2015.

5. Anga G, Barnabas R, Kaminiel O, Tefuarani N, Vince J, Ripa P, Riddell M, Duke T. The aetiology, clinical presentations and outcome of febrile encephalopathy in children in Papua New Guinea. Ann Trop Paediatr. 2010;30:109-18.

6. El-Amin EO, Elbashir MI, Elamin OE, Mukhtar Y, Abdo $\mathrm{H}$, Abdul-Rahman I, El-Amin ME. The underlying aetiologies of coma in febrile Sudanese children. Trans $R$ Soc Trop Med Hyg. 2013;107:307-12.
7. Karmarkar SA, Aneja S, Khare S, Saini A, Seth A, Chauhan BK. A study of acute febrile encephalopathy with special reference to viral etiology. Indian J Pediatr. 2008;75:801-5.

8. Singh RR, Chaudhary SK, Bhatta NK, Khanal B, Shah $D$. Clinical and etiological profile of acute febrile encephalopathy in eastern Nepal. Indian J Pediatr. 2009 ;76:1109-11.

9. Callaham M. Fulminant bacterial meningitis without meningeal signs. Ann Emerg Med. 1989;18:90-3.

10. Fayyaz J, Rehman A, Hamid A, Khursheed M, Zia N, Feroze A. Age related clinical manifestation of acute bacterial meningitis in children presenting to emergency department of a tertiary care hospital. J Pak Med Assoc. 2014 ;64:296-9.

11. Tenembaum S, Chamoles N, Fejerman N. Acute disseminated encephalomyelitis: a long-term follow-up study of 84 pediatric patients. Neurology. 2002;59:1224-31.

12. Armstrong D, Wong B. Central nervous system infections in immunocompromised hosts. Annu Rev Med.1982, 33: 293-308. 
13. Roos KL. Infectious etiologies of altered consciousness. In. Disorders of consciousness. 3rd series. Edited by Young GB \&Wijdicks EFM 2008: 201-216 [Series Editor: Young GB \&Wijdicks EFM, Handbook of Clinical Neurology, Vol. 90.

14. Veltman JA, Bristow CC, Klausner JD. Meningitis in HIV-positive patients in sub-Saharan Africa: a review. J Int AIDS Soc. $2014 ; 17: 19184$.

15. Kleinman ME,Chameides L, Schexnayder SM, et al . Part 14: Pediatric Advanced Life Support: 2010 American Heart Association Guidelines for Cardiopulmonary Resuscitation and Emergency Cardiovascular Care. Circulation. 2010;122(18 supp/ 3):S876-S908

16. Murthy SNK, Faden HS, Cohen ME, Bakshi R. Acute disseminated encephalomyelitis in children. Pediatrics. 2002; 110: e21.

17. Calello DP, Henretig FM. Pediatric toxicology: specialized approach to the poisoned child. Emerg Med Clin North Am. 2014;32:29-52.

18. Brazis PW, Masdeu JC, Biller J. Coma. In. Localization in clinical neurology, $4^{\text {th }}$ Edition, Edited by Brazis PW, Masdeu JC, Biller J eds., $4^{\text {th }}$ ed. Lippincott Williams and Wilkins; Philadelphia, 2001: 559-586.

19. Kirkham FJ, Newton CR, Whitehouse W. Paediatric coma scales. Dev Med Child Neurol. 2008 ;50:267-74.

20. Taylor DA, Ashwal S. Impairment of consciousness and coma. In. Pediatric Neurology: Principles and Practice, $4^{\text {th }}$ edition. Edited by Swaiman KF, Ashwal S, Ferriero DM. Elsevier publications; Philadelphia 2006: 13791400.

21. Marx A, Glass JD, Sutter RW. Differential diagnosis of acute flaccid paralysisand its role in poliomyelitis surveillance. Epidemiol Rev. 2000;22:298-316.

22. Winkler F, Kastenbauer S, Yousry TA, Maerz U, Pfister HW. Discrepancies between brain CT imaging and severely raised intracranial pressure proven by ventriculostomy in adults with pneumococcal meningitis. J Neurol. 2002;249:1292-7.

23. Kirkham FJ. Guidelines for the management of encephalitis in children. Dev Med Child Neurol. 2013;55:107-10.

24. Tunkel AR, Hartman BJ, Kaplan SL, Kaufman BA, Roos KL, Scheld WM, Whitley RJ. Practice guidelines for the management of bacterial meningitis. Clin Infect Dis.2004 30: 1267-1284.

25. KastrupO,Wanke I, Maschke M. Neuroimaging of Infections of the Central Nervous System. Sem Neurol. 2008;28:511-522

26. Domingues RB, Fink MC, Tsanaclis AM, de Castro CC, Cerri GG, Mayo MS, Lakeman FD. Diagnosis of herpes simplex encephalitis by magnetic resonance imaging and polymerase chain reaction assay of cerebrospinal fluid. J Neurol Sci.1998; 157: 148-53.

27. Maschke M, Kastrup O, Forsting M, Diener HC. Update on neuroimaging in infectious central nervous system disease. CurrOpin Neurol. 2004;17:475-480

28. Shen WC, Chiu HH, Chow KC, Tsai CH. MR imaging findings of enteroviral encephalomyelitis: an outbreak in Taiwan. AJNR Am J Neuroradiol.1999;20:1889-1895

29. Misra UK, Kalita J. A comparative study of Japanese and herpes simplex encephalitides.ElectromyogrClin Neurophysiol.1998; 38: 41-46.

30. Abend NS, Chapman KE, Gallentine WB, Goldstein J, Hyslop AE, Loddenkemper T,Nash KB, Riviello JJ Jr, Hahn CD; Pediatric Critical Care EEG Group (PCCEG) and the Critical Care EEG Monitoring Research Consortium (CCEMRC). Electroencephalographic monitoring in the pediatric intensive care unit. Curr Neurol Neurosci Rep. 2013;13:330.

31. Saudubray JM, Sedel F, Walter JH. Clinical approach to treatable inborn metabolic diseases: an introduction. J Inherit Metab Dis. 2006;29:261-74.

32. Pitfield AF, Carroll AB, Kissoon N. Emergency management of increased intracranial pressure. Pediatr Emerg Care. 2012;28:200-4; quiz 205-7.

33. Gwer S, Gatakaa H, Mwai L, Idro R, Newton CR. The role for osmotic agents in children with acute encephalopathies: a systematic review. BMC Pediatr. 2010;10:23.

34. Tiegea XD, Rozenbergb F, Heron B. The spectrum of herpes simplex encephalitis in children. Eur $\mathrm{J}$ PediatrNeurol . 2008;12: $72-81$

35. Sankhyan N, Saptharishi LG, Sasidaran K, Kanga A, Singhi SC. Clinical profile of scrub typhus in children and its association with hemophagocytic lymphohistiocytosis. Indian Pediatr. 2014;51:651-3.

36. Gwer S, Thuo N, Idro R, Ndiritu M, Boga M, Newton $\mathrm{C}$, Kirkham $\mathrm{F}$. Changing trends in incidence and aetiology of childhood acute non-traumatic coma over a period of changing malaria transmission in rural coastal Kenya: a retrospective analysis. BMJ Open. 2012 1;2:e000475.

37. Bokade C, Gulhane R, Bagul A, Thakre S. Acute febrile encephalopathy in children and predictors of mortality. J Clin Diagn Res. 2014 ;8:PC09-11.

38. Zhang WY, Wang LY, Ding F, Hu WB, Soares Magalhaes RJ, Sun HL, Liu YX, Liu QY, Huang LY, Clements AC, Li SL, Li CY. Scrub typhus in mainland China, 20062012: the need for targeted public health interventions. PLoS Negl Trop Dis. 2013;7:e2493.

39. Acestor N, Cooksey R, Newton PN, Ménard D, Guerin PJ, Nakagawa J, Christophel E, González IJ, Bell D. Mapping the aetiology of non-malarial febrile illness in Southeast Asia through a systematic review--terra incognita impairing treatment policies. PLOS One. 2012;7:e44269.

40. Thompson C, Kneen R, Riordan A, Kelly D, Pollard AJ. Encephalitis in children. Arch Dis Child. 2012;97:15061.

41. Birbeck GL, Beare N, Lewallen S, Glover SJ, Molyneux ME, Kaplan PW, Taylor TE. Identification of malaria retinopathy improves the specificity of the clinical diagnosis of cerebral malaria: findings from a prospective cohort study. Am J Trop Med Hyg. 2010 ;82:231-4.

42. Rajapakse S, Rodrigo C, Fernando SD. Drug treatment of scrub typhus. Trop Doct. 2011;41:1-4.

43. Punjabi NH, Hoffman SL, Edman DC, Sukri N, Laughlin LW, Pulungsih SP, Rivai AR, Sututo, Moechtar A, Woodward TE. Treatment of severe typhoid fever in children with high dose dexamethasone. Pediatr Infect Dis J. 1988;7:598-600.

44. Schoeman JF, Donald PR. Tuberculous meningitis. Handb Clin Neurol. 2013;112:1135-8. 